\title{
Extruded and Injection Moulded Virgin PA 6/6 as Abrasion Resistant Material
}

\author{
J. Sukumaran, ${ }^{1}$ R. Keresztes, ${ }^{2}$ G. Kalácska, ${ }^{2}$ H. Almaliki, ${ }^{2}$ P. D. Neis, ${ }^{3}$ and P. De Baets ${ }^{1}$ \\ ${ }^{1}$ Soete Laboratory, Department of Mechanical Construction and Production, Ghent University, Technologiepark 903, \\ 9052 Zwijnaarde, Belgium \\ ${ }^{2}$ Institute for Mechanical Engineering Technology, Faculty of Mechanical Engineering, Szent István University, Gödöllo 2100, Hungary \\ ${ }^{3}$ Laboratory of Tribology, Universidade Federal do Rio Grande do Sul, Porto Alegre, RS, Brazil
}

Correspondence should be addressed to J. Sukumaran; er_jacob1@hotmail.com

Received 9 February 2017; Accepted 27 April 2017; Published 24 May 2017

Academic Editor: Sandhyarani Biswas

Copyright (C) 2017 J. Sukumaran et al. This is an open access article distributed under the Creative Commons Attribution License, which permits unrestricted use, distribution, and reproduction in any medium, provided the original work is properly cited.

\begin{abstract}
Polyamide (PA6/6) is often used as a tribological pair in abrasion prevalent applications such as hinges and sliders. PA6/6 is frequently processed by injection moulding and extrusion process. It is known that these processes influence the polymers mechanical behaviour, but their influence on the polymers wear response has not been studied. Hence the present research attempts to study the influence of different manufacturing processes on tribological behaviour for PA6/6. Wear tests were performed on a pin abrading tester (DIN 50322). Abrasion resistance of both extruded and injection moulded PA6/6 were tested at different loads (20 and $35 \mathrm{~N}$ ). Single-pass (nonoverlapping mode) and multipass testing (overlapping mode) were used to understand the influence of clogging of wear debris. It is evidenced that with increasing load the specific wear rate decreases; moreover, fine abrasives tend to reduce the wear rate. In multipass testing a transfer layer clogged on the counterface that acted as a protective agent and lowers wear rate. Poor mechanical strength of injection moulded polymers is apparently compensated by microstructural response for having a similar wear behaviour between extruded and injection moulded PA 6/6. Hence a proper balance between microstructural and mechanical characteristics is an absolute must in PA 6/6 for better wear performance.
\end{abstract}

\section{Introduction}

Polyamides (PAs) which were introduced in the late ' 30 s were extensively used as engineering plastics in structural application. Among different variants of PAs the most commonly used ones are PA6 and PA6/6. Typical for the last one is the inclusion of additional monomer (diacidic) in the preparation stage [1]. An increased interest in using PAs in tribological application is due to its high mechanical strength and structural integrity. The tribological use of PA for textile machinery, automotive application, and material handling systems was reported earlier [2]. Eventually, it is frequently used for components such as hinges, linear sliders, and ball joints, which experience abrasive wear. These parts are often made by either injection moulding or extrusion. Injection moulding is chosen for complex shapes and high output rates. Extruded parts are often semifinished and may need an extra operation prior to use. The wear response of these two production processes has still not been well reported. It is understood from existing literature that the microstructural change due to the production process may significantly affect the physical characteristics [3]. A crystal structure influenced by the manufacturing process may have consequence in the mechanical characteristics, which in turn may alter the tribological characteristics. However, a manufacturing process is often only selected based on the complexity of the wear part and availability of production facilities and with limited tribological considerations.

The differences in the mechanical properties between injected moulded and extruded polymers basically arise from the structural heterogeneity. Considering the microscale interaction during wear between the polymers and its counterface, the role of structural heterogeneity is still unclear. The increased mechanical characteristics (yield strength) are a consequence of an increase in crystallinity and have been reported elsewhere [4]. A high degree of crystallinity can be expected with moulding [5]. Injection moulding also leads to a certain degree of crystallinity, which is attributed to the 
TABLE 1: Mechanical properties of injection moulded and extruded material specimens.

\begin{tabular}{lcccc}
\hline Mechanical characteristics & Standard & Units & Injection moulded & Extruded \\
\hline Tensile strength & EN ISO 527-2 & $\mathrm{MPa}$ & 69 & 83 \\
Elongation at break & EN ISO 527-2 & $\%$ & 62 & 16 \\
Tensile modulus & EN ISO 527-2 & $\mathrm{MPa}$ & 2050 & 2900 \\
Charpy impact hardness & ISO 179-A & $\mathrm{kJ} / \mathrm{m} 2$ & 49 & 20 \\
Hardness & ASTM D2240 & Shore D & 78.4 & 81 \\
\hline
\end{tabular}

elongation and shear flow where macromolecules align parallel to the mould wall. Anyway, both injection moulding and extrusion result into anisotropic stresses. The polymer tends to consist of different layers with different characteristics; in particular the core of the produced parts strongly differs from the outer skin. Although these surface effects are within the order of micrometres they introduce uncertainty in wear behaviour. With ongoing material removal process the wear behaviour changes because the surface skin and core material have different properties. Normally a uniform behaviour with ongoing wear is desired. This requires homogeneous material characteristics over a depth of some tens of microns. Hence, as was proposed earlier [2], it is necessary to use appropriate processing conditions in order to have better tribological characteristics.

In polymer tribology, apart from mechanical loading several other variables take part in the wear process such as material, surface, and environmental characteristics. Many authors have attempted to study the wear characteristics of the polyamide [4, 6-9], but, nevertheless, the effect of manufacturing process on tribological behaviour are scarcely reported [4]. Most research on polyamide has focused on the influence of additives and strengthening agents [10, 11]. It is evident the mechanical characteristics are a function of the manufacturing process. It has also been shown that wear resistance, and in particular abrasion resistance, can be related to mechanical characteristics [12]. The relation between wear and bulk material properties has already been reported extensively [13]. Practically the hardness of the material is considered for evaluating wear performance. If a relation between hardness and wear holds for metals, for polymers it should be taken with care. It has been shown that a relatively low hardness can result into better wear performance [14]. A more appropriate parameter is the elongation at break. Lancaster has clearly evidenced that the wear rate is inversely proportional to the elongation at break and the breaking strength. Other authors have tried to establish relationships between polymer abrasion resistance and rupture strength, hardness, and tensile strength $[15$, 16]. Also the environmental and geometrical influence on abrasion have been reported earlier [16]. It is concluded that not only the strength properties but also the interfacial properties contribute to the abrasion resistance of polymers. Abrasion being a phenomenon partly dominated by the mechanical interaction of surfaces and abrasives parameters such as shape, size, and sharpness of the abrasive will have an important role [17]. Several authors have studied the influence of size and cohesive strength of abrasives on the abrasion process [16-20].
Knowing that there exists a relationship between tribological characteristics and the crystallinity, which in its turn is controlled by the manufacturing process, is a primary motivation for the present research on tribocharacteristics obtained by different manufacturing processes (extrusion and injection moulding). The selected material for this investigation is virgin PA6/6, fabricated using injection moulded and extrusion process. An attempt is made to understand the influence of the manufacturing process on abrasive wear process. Different loads and abrasive grain sizes have been used for this study.

\section{Materials and Sample Production}

Polyamide 6/6 natural version has been selected because it is frequently used as an engineering material. From the multiple manufacturing processes the two most commonly used processes, injection moulding and extrusion, have been chosen. Both extruded and injection moulded materials were distributed by Quattroplast Ltd., produced by Ensinger $\mathrm{GmbH}$. Concerning the commercial grade PA6/6, only indicative average property values were provided hence the exact material features were measured in-house (see Table 1 ). Tensile modulus at conditioned saturated air ( $\mathrm{RH} 50 \%, 23^{\circ} \mathrm{C}$ ) was made in accordance with the EN ISO 527-2 standard. The average value of five measurements is reported in Table 1. It is evident that the tensile modulus of extruded parts is approximately $35 \%$ higher than that of injected parts. On the other hand the impact strength is $85 \%$ higher for injection moulded parts. The hardness (Shore D) of both materials lies in the same range. It is clear from Table 1 that the manufacturing process has indeed a significant influence on the material properties. This can be attributed to the crystallinity of the material and the molecular orientation [21].

Extruded PA6/6 commercial grade standard plate with $10 \times 500 \times 1000 \mathrm{~mm}$ was used from which the middle section with $120 \times 150 \mathrm{~mm}$ was cut out. The injection moulded specimens were extracted from plates of $10 \times 120 \times 150 \mathrm{~mm}$. Having the $10 \times 120 \times 150 \mathrm{~mm}$ plates, further step was the machining of the mechanical and tribological test specimens with the same controlled technology; thus the extra stresses caused by machining had to be approximately the same. For the tribological specimens the plates were initially cut (rough) to a dimension of $10 \times 120 \times 150 \mathrm{~mm}$ and further reduced to $10 \times 10 \times 120 \mathrm{~mm}$ by means of band saw. Subsequently the test specimens $(\varnothing 8 \times 18)$ were machined (no cooling, dry cutting) at a cutting speed of $40 \mathrm{~m} / \mathrm{min}$ using a centre lathe. It is found in literature that the crystallinity affects the skin layer, which in turn may have consequences on 

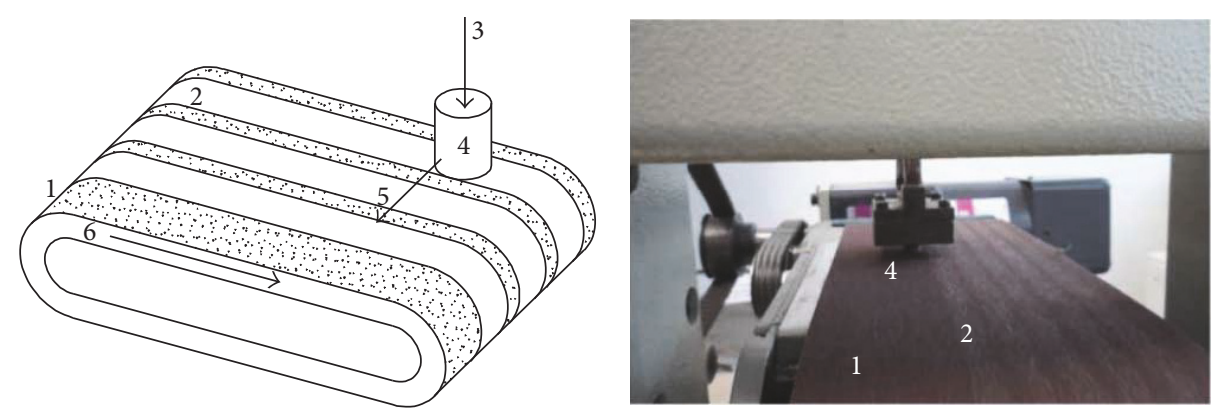

Figure 1: Schematics of the test setup (1) abrasive paper; (2) wear track; (3) normal force $\left(F_{N}\right)$; (4) polymer pin; (5) cross-feed; (6) sliding direction.

tribological characteristics [5]. It has been earlier reported that, in the process of specimen preparation, the machining of polymers favours uniformity in morphology by removing the nonspherulitic and transition region in the surface [4]. Hence, the tribo specimens are taken out of the extruded and injection moulded slabs by machining. Finally the finishing operations were performed on a NCT EUROturn-12B CNC turning centre. In order to maintain uniform surface character a constant feed rate $(0.1 \mathrm{~mm} / \mathrm{rev})$, depth of cut $(1 \mathrm{~mm})$, and cutting speed $(50 \mathrm{~m} / \mathrm{min})$ were maintained for all the specimens in the final finishing operation.

\section{Experimental Methods}

Frequently PA6/6 has been used in applications (hinges, sliders, etc.) where two-body abrasion is prevalent; hence the present research focuses on the same. A test procedure was adopted according to DIN 50322 (ASTM G132 category) and realized through a test setup that has been designed and constructed at Szent Istvan University, Hungary [10]. In the test configuration a cylindrical test specimen $(\varnothing 8 \mathrm{~mm}$ and length $18 \mathrm{~mm}$ ) is loaded against the moving abrasive paper (sliding speed of $0.08 \mathrm{~m} / \mathrm{s}$ ) with a predetermined normal force (range: $20-35 \mathrm{~N}$ ). The mechanical interaction between the hard abrasive particles and the soft polymer tends to induce abrasion. The height loss of the specimen due to abrasion is monitored online using a displacement transducer. The schematic of the test setup is showed in Figure 1. The unique feature of the test setup is that the capability of performing test under both multipass (continuous overlapping) and single-pass (nonoverlapping) wear tracks, which is realized by means of a cross-feed. With the singlepass wear track the polymer contact surface always interacts with fresh abrasives; hence the uncertainty caused by rolling of abrasives, clogging of wear debris on the abrasive paper, and breakage of abrasives is negligible. In the single-pass test a helical pattern with parallel wear tracks was followed at constant surface velocity.

Two different sizes of abrasive particles $\left(\mathrm{SiO}_{2}\right)$ are used to study the size effect in abrasion process. P240 and P100 abrasive sheets, corresponding to a particle size of $58.5 \mu \mathrm{m}$ and $162 \mu \mathrm{m}$, were used. The influence of clogging of wear debris on the abrasive surface was studied by comparing the overlapping and nonoverlapping wear tracks generated
TABLE 2: Wear test conditions.

\begin{tabular}{lc}
\hline Test variables & Levels used for the test variables \\
\hline Material production & Injection moulded PA6/6 \\
& Extruded PA6/6 \\
Abrasive paper $\left(\mathrm{SiO}_{2}\right.$ particle & $\mathrm{P} 100(162 \mu \mathrm{m})$ \\
size $)$ & $\mathrm{P} 240(58.5 \mu \mathrm{m})$ \\
Load $[\mathrm{N}]$ (contact pressure & $20(0.7)$ \\
$[\mathrm{MPa}])$ & $35(1.0)$ \\
& Nonoverlapping $(5.5)$ \\
Wear track (sliding distance $[\mathrm{m}])$ & Overlapping $(50)$ \\
Sliding velocity $[\mathrm{m} / \mathrm{s}]$ & 0.08 \\
\hline
\end{tabular}

through multipass and single-pass testing, respectively. Both materials (i.e., the injection moulded and the extruded samples) were tested for two different loading conditions $20 \mathrm{~N}$ and $35 \mathrm{~N}$ (corresponding to $0.7 \mathrm{MPa}$ and $1 \mathrm{MPa}$ contact pressure). The sliding velocity is kept constant at $0.08 \mathrm{~m} / \mathrm{s}$ throughout the experiment. Table 2 provides the experimental matrix. Three repeats were performed to determine repeatability and scatter (standard deviation) of the wear data. The surface characteristics of the polymers were investigated with reflected light bright field optical microscopy. 3D surface profiles were studied using white light interferometry (Taylor Hobson CCI). Postmortem analysis after wear testing using WAXD was performed for both injection moulded and extruded samples. XRD tests were carried out with a BRUKER Diffractometer on an $8 \mathrm{~mm}$ diameter and $2 \mathrm{~mm}$ thick samples cut from the abraded injection moulded and extruded pins.

In the review paper of Briscoe different models of abrasive wear are proposed [22]. The various models used in the wear of polymer are listed in Table 3. The Archard model is universally accepted for all materials where the hardness plays an effective role in the wear process. However, as understood from Shipway and Ngao [14], the hardness may not be a critical parameter in polymer abrasion, and additional parameters (surface velocity and sliding duration) are introduced with the Lewis and Rhee model. Most of these models are built for adhesive wear. In this research the specific wear rate as given in Table 3 is used to study the wear performance. 
TABLE 3: Wear models for polymers.

\begin{tabular}{|c|c|c|}
\hline Wear model & Description & Variables \\
\hline $\begin{array}{l}\text { Archard } \\
\text { Lewis } \\
\text { Rhee } \\
\text { Kar and Bahadur } \\
\text { Specific wear rate }\end{array}$ & $\begin{array}{c}\Delta V=K\left(\frac{W d}{H}\right) \\
\Delta V=K N v T \\
W=K P^{a} V^{b} T^{c} \\
\Delta V=\frac{K \gamma^{1.775} P^{1.47} L_{1}^{1.25}}{\Delta E^{3.225}} \\
\Delta V=k_{0} N d\end{array}$ & $\begin{array}{l}K: \text { dimensionless wear factor for Archard, Lewis, Rhee and Kar } \\
k_{0}: \text { specific wear rate }\left[\mathrm{m}^{3} / \mathrm{N}-\mathrm{m}\right] \\
\Delta V: \text { wear volume }\left[\mathrm{m}^{3}\right] \\
W: \text { weight loss }[\mathrm{g}] \\
N: \text { normal load }[\mathrm{N}] \\
P: \text { contact pressure } \mathrm{MPa} \\
H: \text { hardness } \\
d: \text { sliding distance } \\
v: \text { sliding speed }[\mathrm{m} / \mathrm{s}] \\
T: \text { sliding duration }[\mathrm{s}] \\
L_{1}: \text { sliding distance } \\
E: \text { Young's modulus of elasticity } \\
\gamma: \text { surface energy } \\
a, b, c: \text { exponents }\end{array}$ \\
\hline
\end{tabular}

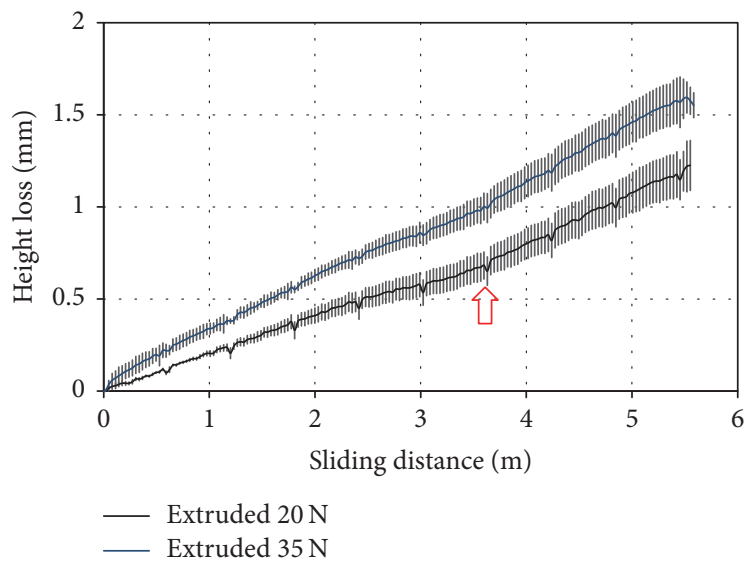

(a)

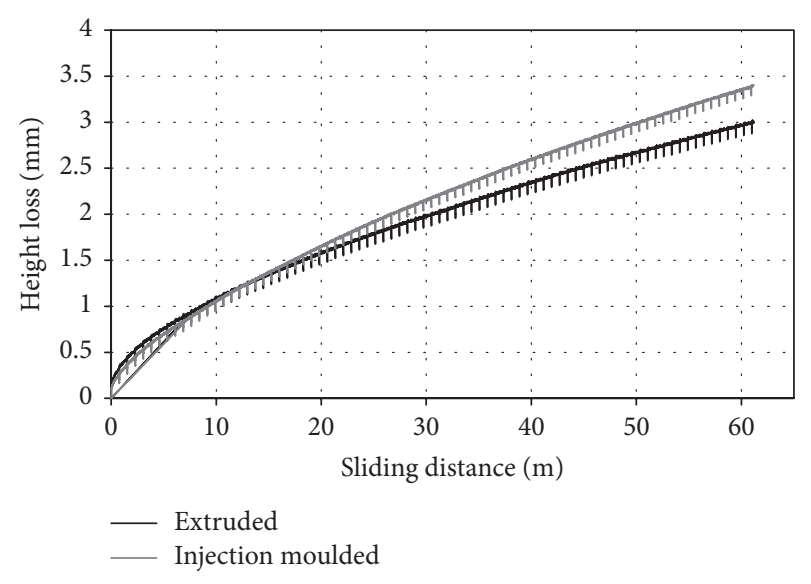

(b)

FIGURE 2: Height loss as a function of time. (a) Extruded sample (E) $(20 \mathrm{~N}$ and $35 \mathrm{~N})$ tested with single pass using P100. (b) Extruded and injection moulded sample $(20 \mathrm{~N})$ tested with multipass using P100.

\section{Results and Discussion}

4.1. Wear Mechanisms. The repeatability tests clearly show that the standard deviation of the wear results is small enough to distinguish significant difference in wear behaviour at the different tribological conditions mentioned in Table 2. Figure 2(a) shows the height loss due to wear. It is clear that the height loss is significantly larger at higher normal load. Figure 2(a) shows that the height loss follows a linear trend with time for both loading conditions. As the contact pressure is kept constant throughout the whole test, also the wear volume curve is linear. The small dips in the wear curves of Figure 2(a) (see arrows) are caused by the crossfeed applied for obtaining the continuous helicoidal wear pad. The multipass overlapping tests showed a difference in wear trend when compared to the single-pass testing. In multipass testing (see Figure 2(b)) a clear running-in period (7 to $10 \mathrm{~m}$ sliding distance) can be observed. This higher wear rate for the running-in period can be attributed to the deposition of polymer on the abrasive paper, referred to as "clogging" [19]. After the running-in period the wear rate stabilizes and a quasi-linear wear trend is observed, for both injection moulded and extruded specimens (see Figure 2(b)). It can be concluded that the deposition of wear debris on the abrasive surface reduces the wear rate, after a certain critical layer thickness is obtained (hereafter 7 to $10 \mathrm{~m}$ sliding distance). The debris trapped on the abrasive paper acts as a protective agent. Earlier reports by Harsha and Tewari [19] show a similar behaviour for PEEK composites, where the wear curve for multipass testing also has an initial rapid increase and then subsequently stabilizes.

The specific wear for both single-pass and multipass conditions was calculated using the specific wear rate $\left(k_{0}\right)$. The dimensionless $K$-value was in the order of $10^{10} \mathrm{~m}^{3} / \mathrm{N}-\mathrm{m}$. As it was mentioned earlier that the Archard model does not hold good for polymers [19], we have chosen the specific wear rate with reference to the literature [23]. The wear indicators from specific wear rate $\left(k_{0}\right)$ are shown in Table 4 . However, calculations were also made for the other models such as Archard, Rhee, and Lewis where similar tendency to that of the specific wear rate was observed for the influence of load and grain size. Plots from specific wear rate are given as a representative for indicating the wear trend for different conditions of load and abrasive paper. 


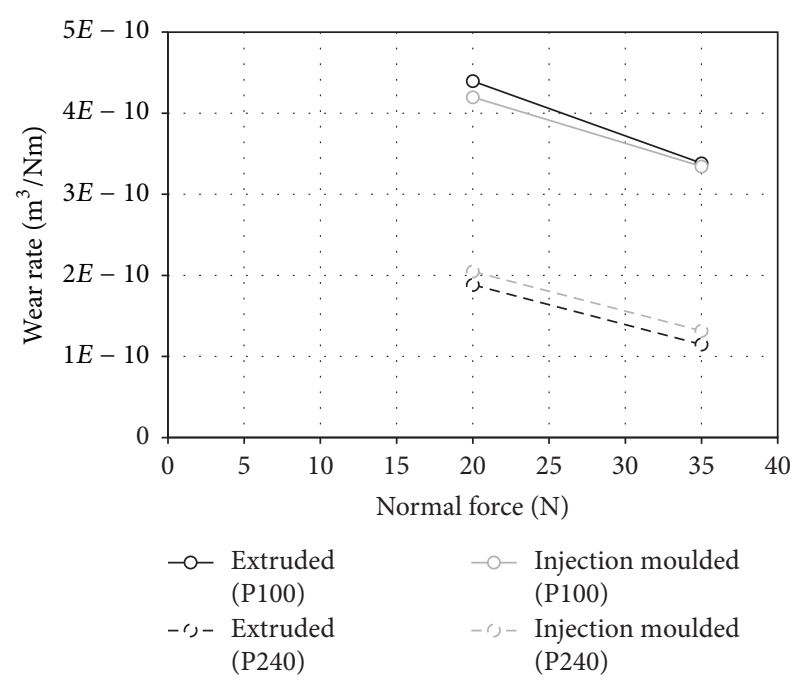

(a)

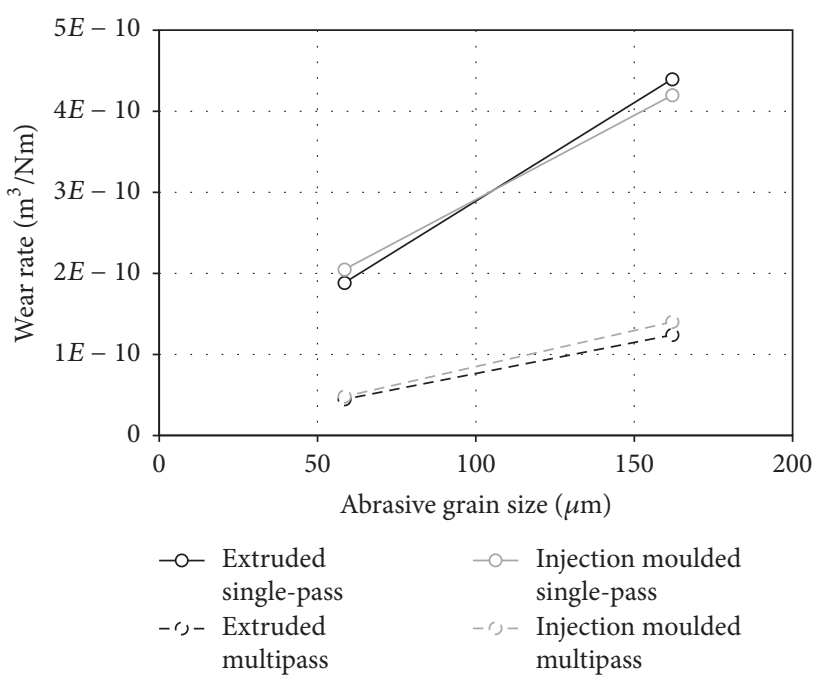

(b)

FIGURE 3: Specific wear rate: (a) influence of load and (b) influence of grain size.

TABLE 4: Specific wear rate for extruded and injection moulded PA6/6.

\begin{tabular}{lcccc}
\hline $\begin{array}{l}\text { Contact } \\
\text { condition }\end{array}$ & $\begin{array}{c}\text { Abrasive } \\
\text { paper }\end{array}$ & $\begin{array}{c}\text { Load } \\
{[\mathrm{N}]}\end{array}$ & \multicolumn{2}{c}{ Specific wear rate $k_{0}\left[\mathrm{~m}^{3} / \mathrm{N}-\mathrm{m}\right]$} \\
& $\mathrm{P} 100$ & 20 & $4.39 E-10$ & $4.19 E-10$ \\
\multirow{3}{*}{ Single-pass } & & 35 & $3.38 E-10$ & $3.34 E-10$ \\
& $\mathrm{P} 240$ & 20 & $1.88 E-10$ & $2.04 E-10$ \\
& & 35 & $1.14 E-10$ & $1.31 E-10$ \\
\hline \multirow{2}{*}{ Multipass } & $\mathrm{P} 100$ & 20 & $1.24 E-10$ & $1.40 E-10$ \\
& $\mathrm{P} 240$ & 20 & $4.47 E-11$ & $4.81 E-11$ \\
\hline
\end{tabular}

It is clearly seen in Figure 3(a) that the wear rate is lower for increased normal load. This was observed for both the extruded and injection moulded material and also for P100 and P240 abrasive papers. Similar results have been reported by Harsha that a decrease in wear rate as a function of increasing normal load (beyond $10 \mathrm{~N}$ ) was observed for PEI and Epoxy in three-body abrasion [23]. Lhymn also reported a lower wear rate with higher normal load [24]. These authors also relate this counterintuitive wear trend to the low sliding speed, where thermal activation of the surfaces does not occur. It is noteworthy to mention here that the sliding speed $(0.08 \mathrm{~m} / \mathrm{s})$ in the present research is far inferior when compared with the conditions where thermal activation of surfaces is prevalent. In this work the inverse relation between wear rate and normal load should also be put in relation to the low sliding speed. Besides the influence of load, the influence of grain size was also investigated. Figure 3(b) shows the specific wear against the average grain size. For both the extruded and injection moulded specimen a higher wear was found with increasing grain size. A similar wear trend for PA6/6 with decreasing grit size resulting in decreased wear rate was reported earlier for PA6/6 [25]. It is noteworthy to point out that this mechanism is valued to other semicrystalline polymers PET [17].

This relation is more pronounced in single-pass conditions (see Figure 3(b)) than in multipass conditions. It is evident that in multipass condition the worn debris tends to form a thin layer polymer. Hence the direct aggressive actions of abrasives are partly reduced by the thin layer to have reduced wear rate. Comparing the wear profile for extruded specimens in Figure 2, it is evident that the wear rate has reduced up to $50 \%$ in the single-pass testing when compared to the multipass testing. A similar result was earlier published where a significant difference was found between the single and multipass testing for PA6/6 and polycarbonate [26]. The relation between abrasion and grain size was also studied earlier where it is evidenced that an increase in abrasive size leads to a change in mechanism from ploughing to cutting [27].

From Figure 3 it is immediately clear that there is only limited difference in the wear rate between extruded and injection moulded specimens. On the other hand the production process (extrusion, injection) has significant influence on mechanical characteristics, such as tensile modulus (see Table 1). It is known earlier that the abrasion of polymers relies greatly on the physical properties of the material [20]. These findings lead to the conclusion that there is no direct relation between mechanical properties and abrasive wear behaviour. Rather a relation between abrasive wear and microstructure should be identified.

Harsha [23] has studied the influence of microstructural parameters such as molecular orientation and degree of crystallinity on wear mechanisms. In Harsha's investigation on PA-fibres Harsha did not find any correspondence between the molecular weight and macroscopic wear (abrasion) and damage mechanisms. However, they concluded that there is clear correlation between molecular orientation and wear resistance [28]. More specifically they indicate a correlation 


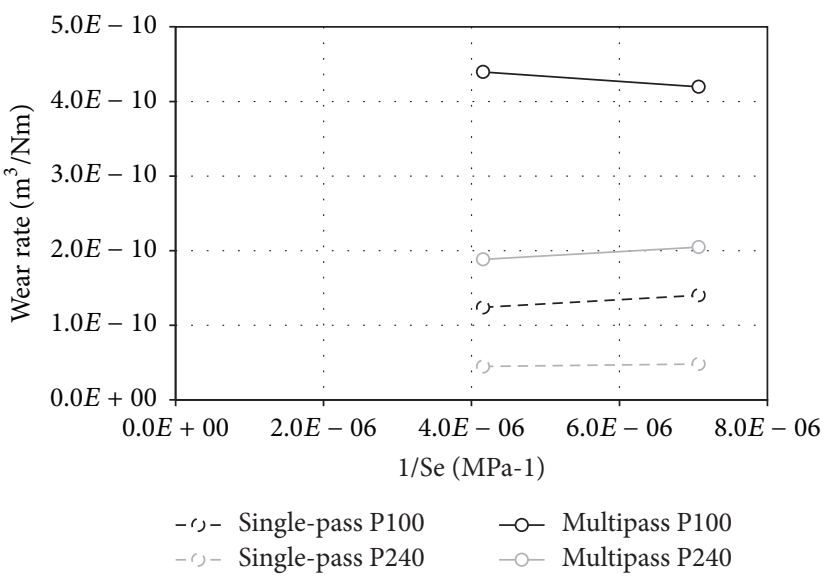

(a)

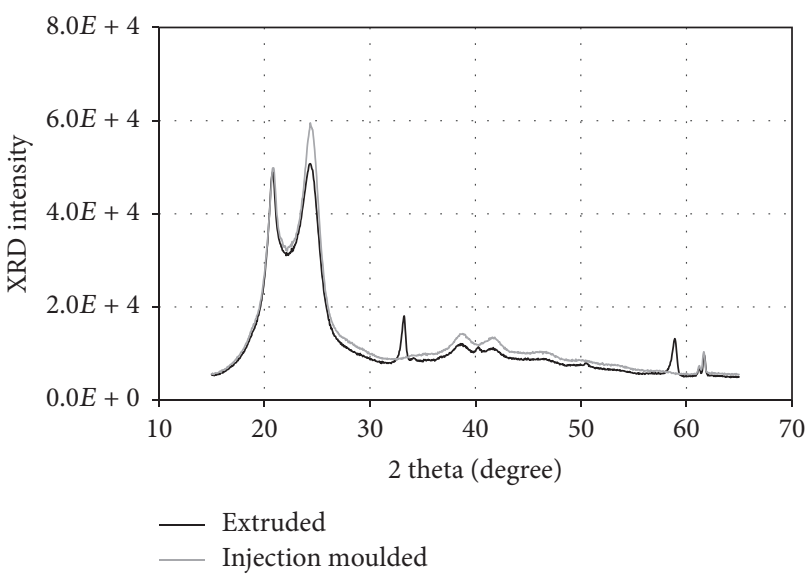

(b)

Figure 4: (a) Specific wear as a function of 1/Se (20 N normal force) and (b) XRD (WAXD) of unworn injection moulded and extruded samples.

between molecular orientation and damage and between microvoids in the amorphous region and wear. From literature it is evident that the molecular orientation is process dependent and thus different for extruded and injection moulded parts. In Figure 4 the results are organized in such a way that wear is plotted against mechanical characteristics (inverse of product of ultimate tensile strength (S) and the elongation at break (e)) for different contact paths (singlepass, multiple-pass) and grain sizes.

Even though there is difference in mechanical characteristics between the extruded and the injection moulded specimens, the wear rate between the two materials remains similar. This may lead to the hypothesis that the microstructure is the true cause for difference in wear behaviour. This hypothesis will now be evidenced by XRD evaluation of the worn specimens. The XRD spectra of both the extruded and injection moulded specimen are presented in Figure 4(b). A narrow peak is present for both materials at $\theta=20.7^{\circ}$ and $\theta=24.3^{\circ}$ representing $\gamma$ and $\alpha$ phases, respectively. This also corresponds to the XRD-results presented in the existing literature [29]. The peak intensity at $\theta=24.3^{\circ}$ is similar (no significant difference) for the extruded sample and injection moulded specimens. The additional peaks for the extruded samples at $33.2^{\circ}$ and $58.9^{\circ}$ indicate the difference in molecular orientation between the two materials. It is thus justified to consider that polymers manufactured by injection moulding have different molecular orientation than extruded samples. This is particularly true because with extrusion a deliberate orientation is achieved but while in case of injection moulding the orientation is rather incidental and may result from the melting and solidifying process.

Literature reports indicate the high degree of crystallinity resulting from moulding [5]. Materials with increased $\alpha$ crystals have a more close packing and hence also higher mechanical strength. This is however not the case with the present material where on the one hand no significant difference in $\alpha$-crystal phase is noticed but a difference in mechanical strength is measured (injection moulded specimen has a lower strength). The similar wear behaviour for both the polymers is from the combined property of mechanical strength and the molecular orientation. This research serves as a starting point for identifying the qualitative connection between tribological characteristics and molecular orientation; however, a precise correlation between the same is the next step of this research.

4.2. Surface Characteristics. Figure 5 shows the surface characteristics of a worn extruded and injection moulded specimen. Groove-like microchannels are present on the whole surface. From macroscopic inspection as seen in Figure 5 the abrasive wear mechanism are microcutting and ploughing. With the higher magnification in Figures 6 and 7 a dominant microcutting process becomes clear. Curling of debris due to the micromachining of the polymer surface by the $\mathrm{SiO} 2$ abrasives has led to the formation of microfibrils. A micrograph of such a fibril is clearly shown in Figure 6. These microfibrils with ongoing wear process comingle to form a sheet which is rigidly attached to the circumference (periphery) of the cylindrical pin. Similar feature with the formation of microfibrils during the abrasion process was reported by several authors $[18,19,30]$. The mechanism of particle generation may change significantly differing depending on the material characteristics. Figure 6 as observed from the optical microscopy of extruded samples shows the microcutting behaviour of polymers from the long thin fibrils. The photomicrographs (see Figure 5) clearly display this difference: the microfibrils formed in case of extruded specimens are significantly larger compared with injection moulded pins. The worn surfaces were then investigated at a higher magnification using a reflected light optical microscopy. Figure 7(a) reveals deep grooves in case of injection moulded specimens (indicated with arrow mark). Beside microcutting wedge formation is also scarcely noticed (see Figure 7(b), marked with red circle). Analogue deep grooves are not found to the same extent on the extruded pins. Since both the materials were virgin matrix 


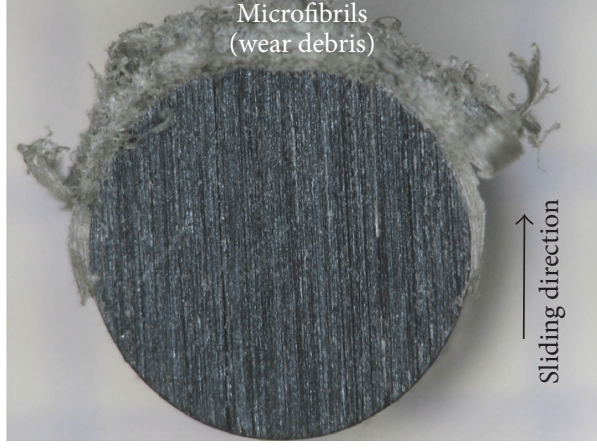

(a)

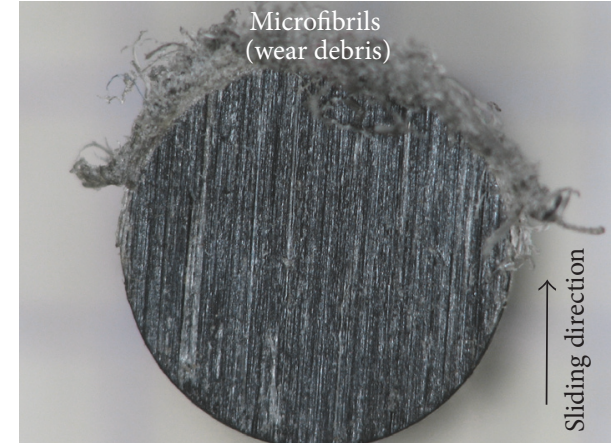

(b)

Figure 5: Photomacrograph of worn PA6/6-surface (counterface P240 and 20 N normal force): (a) extruded pins; (b) injection moulded pins.

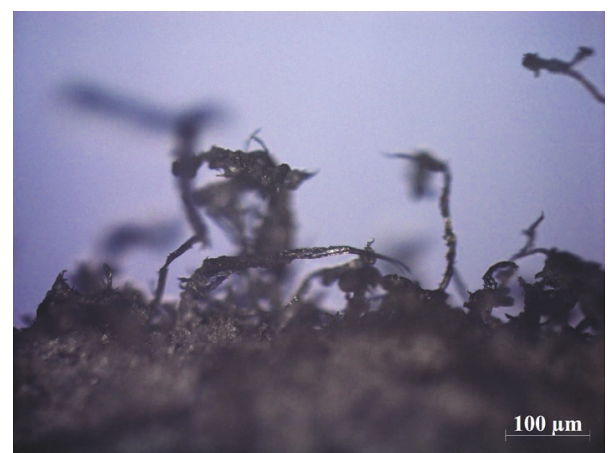

FIGURE 6: Fibril at the periphery of the extruded moulded pin.

the particulate debris was not present in the contact surface. A uniform pattern of the grooving with smooth continuous grooves was present for both the extruded and the injection moulded specimen contact surface. These qualitative findings are further quantified in Section 4.2.

The 3D profile of the worn surfaces observed using white light interferometry (Taylor Hobson CCI) is shown in Figure 8. It is immediately clear that the surfaces of the injection moulded pins have deeper grooves (up to $130 \mu \mathrm{m}$ deep) than the extruded pins (up to $65 \mu \mathrm{m}$ ). The 3D surface roughness of injection moulded specimen ( $\mathrm{Sa}=8.96 \mu \mathrm{m}$, $\mathrm{Sz}=82.94 \mu \mathrm{m})$ is approximately half of the roughness of extruded pins ( $\mathrm{Sa}=17.03 \mu \mathrm{m}, \mathrm{Sz}=170.2 \mu \mathrm{m}$ ). It is clear that both surfaces have been subjected to microcutting as is also evidenced by the debris present at the periphery of the contact area. Wide shallow grooves, which are characteristic for local plastic deformation, are not found on any of the surfaces. This allows us to conclude the dominant mechanism in both cases is microcutting. It is clear from the $3 \mathrm{D}$ profile that the depth profile indentation caused by the abrasive particle between the injection moulded and the extruded specimen is different. And one may conclude that the microcutting phenomenon is severe for the injection moulded pins. Few regions with ridges also indicate a mild action of microploughing phenomena. Nevertheless, the holistic analysis from the optical microscopy, visual inspection, and the white light interferometry shows a dominant microcutting mechanism.

\section{Conclusions}

Wear properties of PA6/6 manufactured by extrusion and injection moulding, respectively, were investigated. Based on the wear measurements, the corresponding surface investigation, and additional literature study, the following conclusions can be drawn:

(i) An increase in normal force leads to a decrease of the wear rate, provided that the tests are performed at slow sliding speed.

(ii) Larger abrasive grain size leads to significantly larger wear rate.

(iii) The difference in abrasion resistance between the injection moulded specimen and extruded parts can be explained based on mechanical properties and molecular orientation.

(iv) PA6/6 manufactured with injection moulding and extrusion may possess different molecular orientation. The effects of molecular orientation on wear may (over)compensate the difference caused by mechanical properties.

(v) The influence of molecular orientation is evident. However it requires more studies to precisely relate molecular orientation to abrasion resistance.

(vi) The things presented including the specific wear rate do not account for details such as molecular orientation results and should be adapted accordingly.

(vii) The surface roughness after wear is twice as large for injection moulded compared to extruded specimens. Nevertheless, both materials have undergone microcutting as dominant wear mechanism.

\section{Conflicts of Interest}

The authors declare that they have no conflicts of interest. 


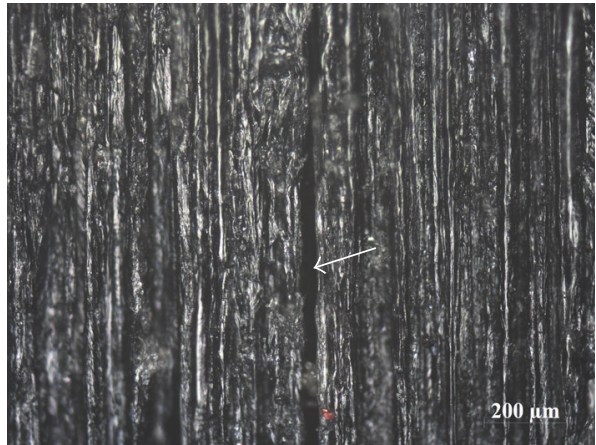

(a)

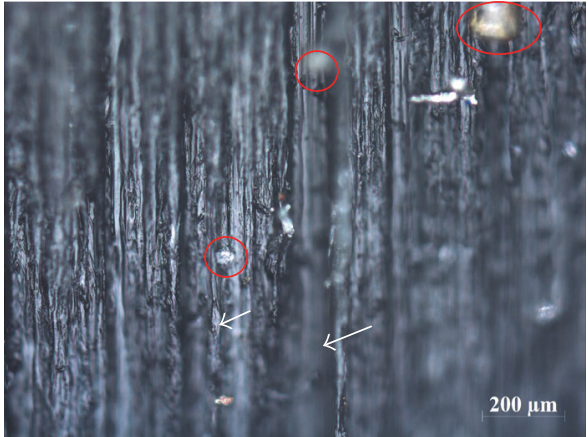

(b)

Figure 7: Micrographs of worn contact surface (counterface P240 and normal load 20 N): (a) extruded pins and (b) injection moulded pins.

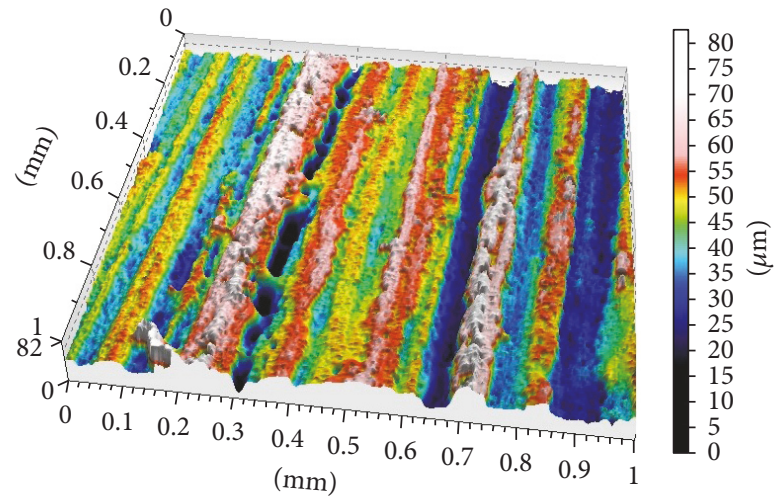

(a)

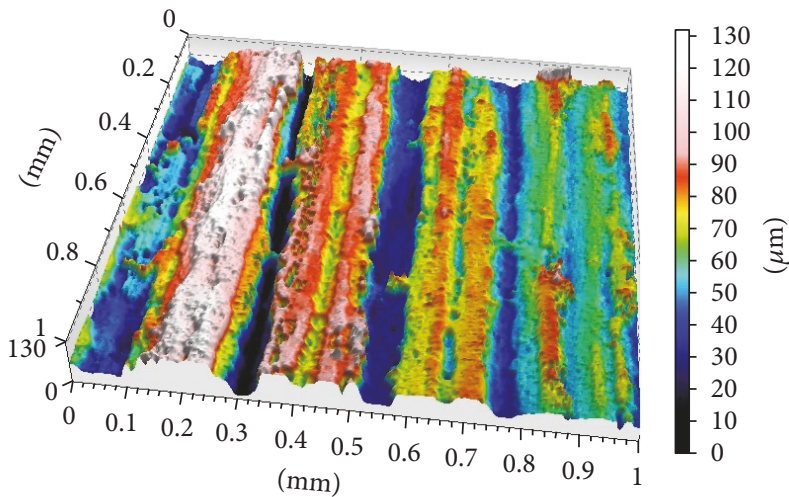

(b)

FIGURE 8: 3D topography of worn contact surface (P240, normal load $20 \mathrm{~N}$ ): (a) extruded pins and (b) injection moulded pins.

\section{Acknowledgments}

The authors would like to acknowledge Ranjith Karuparambil Ramachandran from CoCOON, Ghent University, for his support on XRD investigation and OTKA K113039 Research Fund, Hungary, for supporting the tests.

\section{References}

[1] C. A. Harper, Handbook of Plastics, Elastomers, and Composites, vol. 2, McGraw-Hill, NY, USA, 1996.

[2] R. T. Steinbuch, "Nylon 6 as a bearing material," Wear, vol. 5, no. 6, pp. 458-466, 1962.

[3] X. C. Wang, Q. Zheng, and G. S. Yang, "Influence of preparation methods on structure and properties of PA6/PA66 blends: a comparison of melt-mixing and in situ blending," Journal of Polymer Science, Part B: Polymer Physics, vol. 45, no. 10, pp.11761186, 2007.

[4] S. Apichartpattanasiri, J. N. Hay, and S. N. Kukureka, "A study of tribological behaviour of polyamide 66 with varying injectionmoulding parameters," Wear, vol. 250-251, no. 2, pp. 1557-1566, 2001.

[5] L. Sawyer, D. Grubb, and G. F. Meyers, Polymer Microscopy, Springer Science \& Business Media, Berlin, Germany, 2008.

[6] S. M. Aharoni, "Wear of polymers by roll-formation," Wear, vol. 25, no. 3, pp. 309-327, 1973.
[7] E. Basavaraj, B. Ramaraj, J.-H. Lee, and Siddaramaiah, "Polyamide 6/carbon black/molybdenum disulphide composites: friction, wear and morphological characteristics," Materials Chemistry and Physics, vol. 138, no. 2-3, pp. 658-665, 2013.

[8] M. D. Bermdez, F. J. Carrin-Vilches, I. Martnez-Mateo, and G. Martnez-Nicols, "Comparative study of the tribological properties of polyamide 6 filled with molybdenum disulfide and liquid crystalline additives," Journal of Applied Polymer Science, vol. 81, no. 10, pp. 2426-2432, 2001.

[9] G. Kalácska, "An engineering approach to dry friction behaviour of numerous engineering plastics with respect to the mechanical properties," Express Polymer Letters, vol. 7, no. 2, pp. 199-210, 2013.

[10] M. Andó, G. Kalácska, and T. Czigány, "Development and Examination of different cast polyamide 6 composites," Synergy and Technical Development, pp. o6-199, 2010.

[11] M. Andó, G. Kalácska, and T. Czigány, "Dynamic mechanical tests on magnesium catalyzed cast polyamide 6 composites having different additives," Materials Science Forum, vol. 659, pp. 269-275, 2010.

[12] B. J. Briscoe and S. K. Sinha, "Tribology of polymeric solids and their composites," in Wear-Materials, Mechanisms and Practice, pp. 223-267, John Wiley \& Sons, NJ, USA, 2005.

[13] G. W. Stachowiak, Wear: Materials, Mechanisms and Practice, John Wiley \& Sons, NJ, USA, 2006.

[14] P. H. Shipway and N. K. Ngao, "Microscale abrasive wear of polymeric materials," Wear, vol. 255, no. 1-6, pp. 742-750, 2003. 
[15] J. K. Lancaster, "The effect of carbon fibre reinforcement on the friction and wear of polymers," Journal of Physics D: Applied Physics, vol. 1, no. 5, article no. 303, pp. 549-559, 1968.

[16] H. Czichos, "Influence of adhesive and abrasive mechanisms on the tribological behaviour of thermoplastic polymers," Wear, vol. 88, no. 1, pp. 27-43, 1983.

[17] K. Friedrich and M. Cyffka, "On the wear of reinforced thermoplastics by different abrasive papers," Wear, vol. 103, no. 4, pp. 333-344, 1985.

[18] R. Cortellucci, C. J. Heim, T. D. Koshy, and P. J. Phillips, "Abrasion of plastics," Wear, vol. 47, no. 2, pp. 397-405, 1978.

[19] A. P. Harsha and U. S. Tewari, "Two-body and three-body abrasive wear behaviour of polyaryletherketone composites," Polymer Testing, vol. 22, no. 4, pp. 403-418, 2003.

[20] M. Vaziri, R. T. Spurr, and F. H. Stott, "An investigation of the wear of polymeric materials," Wear, vol. 122, no. 3, pp. 329-342, 1988.

[21] V. A. Bely, V. G. Savkin, and A. I. Sviridyonok, "Effect of structure on polymer friction," Wear, vol. 18, no. 1, pp. 11-18, 1971.

[22] B. Briscoe, "Wear of polymers: an essay on fundamental aspects," Tribology International, vol. 14, no. 4, pp. 231-243, 1981.

[23] A. P. Harsha, "An investigation on low stress abrasive wear characteristics of high performance engineering thermoplastic polymers," Wear, vol. 271, no. 5-6, pp. 942-951, 2011.

[24] C. Lhymn, "Effect of normal load on the specific wear rate of fibrous composites," Wear, vol. 120, no. 1, pp. 1-27, 1987.

[25] H. Unal, U. Sen, and A. Mimaroglu, "Abrasive wear behaviour of polymeric materials," Materials and Design, vol. 26, no. 8, pp. 705-710, 2005.

[26] J. C. Roberts and C. Heh-Won, "Two-body abrasion of some polymers against $6-50 \mu \mathrm{m} \mathrm{SiC} \mathrm{abrasives,"} \mathrm{Wear,} \mathrm{vol.} \mathrm{79,} \mathrm{no.} \mathrm{3,}$ pp. 363-374, 1982.

[27] J. D. Huffington, "Abrasion groove sizes and shapes in relation to the mechanism of abrasion," Wear, vol. 49, no. 2, pp. 327-337, 1978.

[28] J. Cayer-Barrioz, D. Mazuyer, P. Kapsa, A. Chateauminois, and G. Robert, "Abrasive wear micromechanisms of oriented polymers," Polymer, vol. 45, no. 8, pp. 2729-2736, 2004.

[29] H. C. Y. Cartledge and C. A. Baillie, "Effects of crystallinity, transcrystallinity and crystal phases of GF/PA on friction and wear mechanisms," Journal of Materials Science, vol. 37, no. 14, pp. 3005-3022, 2002.

[30] K. Tanaka, Y. Uchiyama, and S. Toyooka, "The mechanism of wear of polytetrafluoroethylene," Wear, vol. 23, no. 2, pp. 153$172,1973$. 


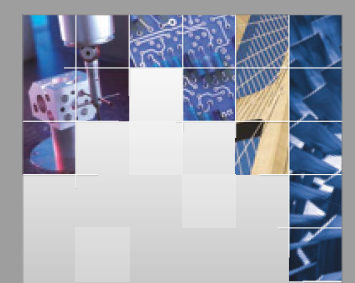

\section{Enfincering}
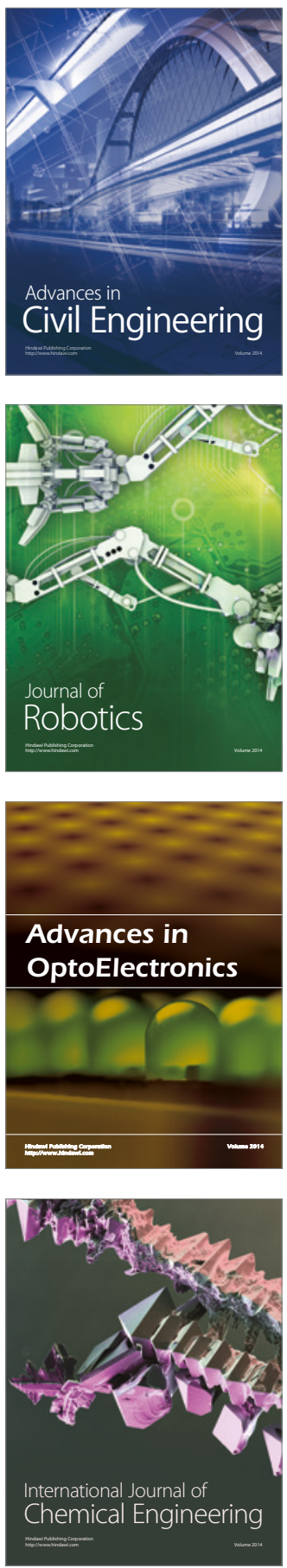

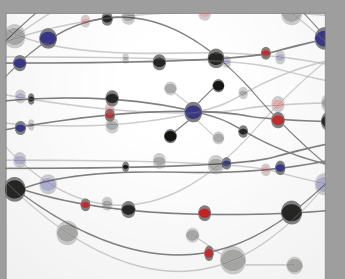

The Scientific World Journal

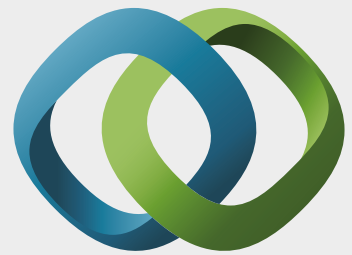

\section{Hindawi}

Submit your manuscripts at

https://www.hindawi.com
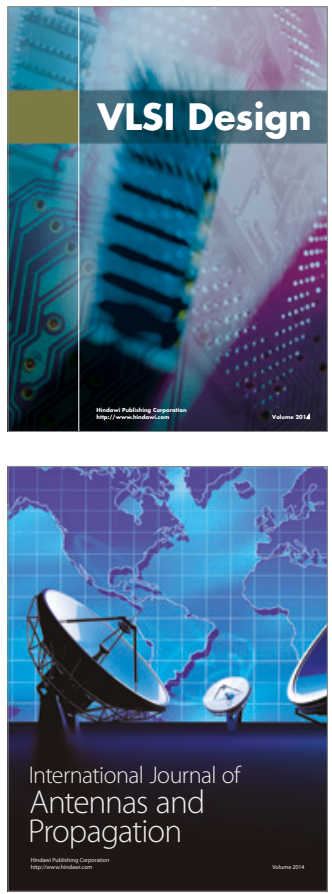

\section{Rotating}

Machinery
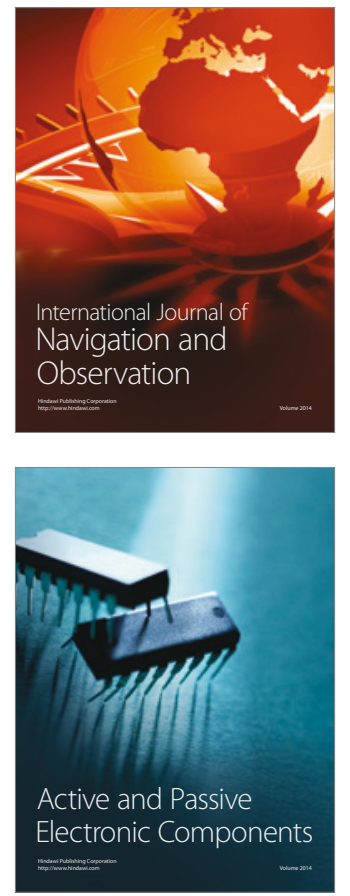
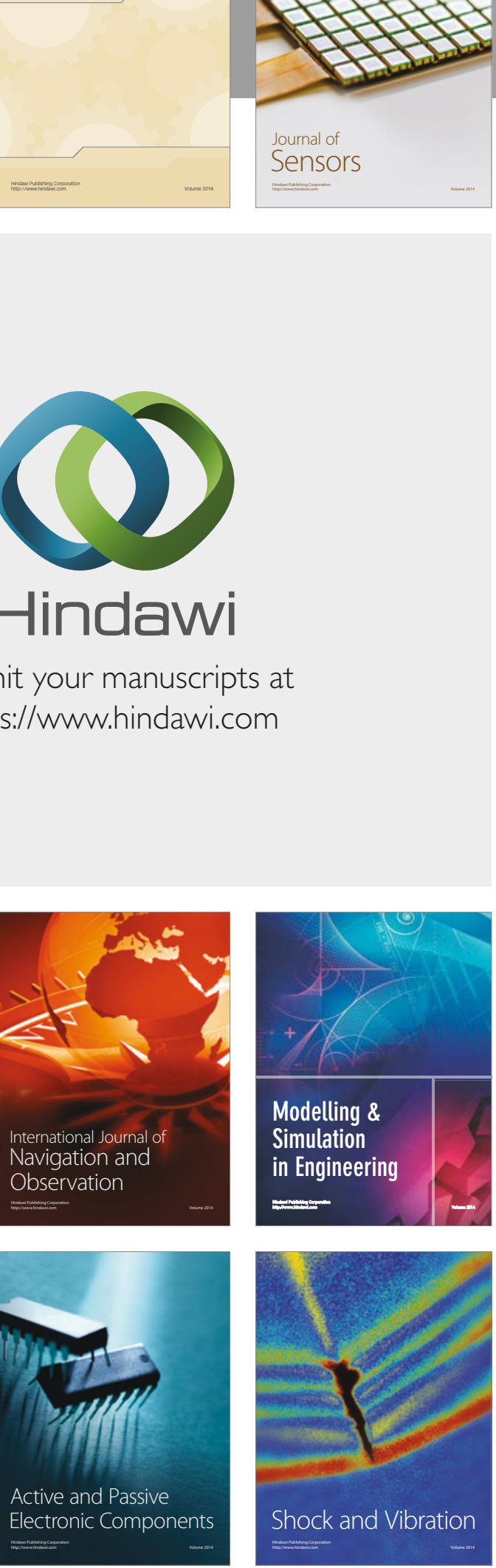
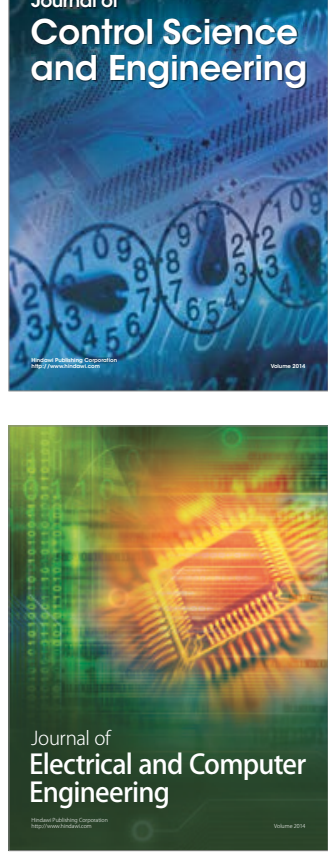

Distributed

Journal of

Control Science

and Engineering
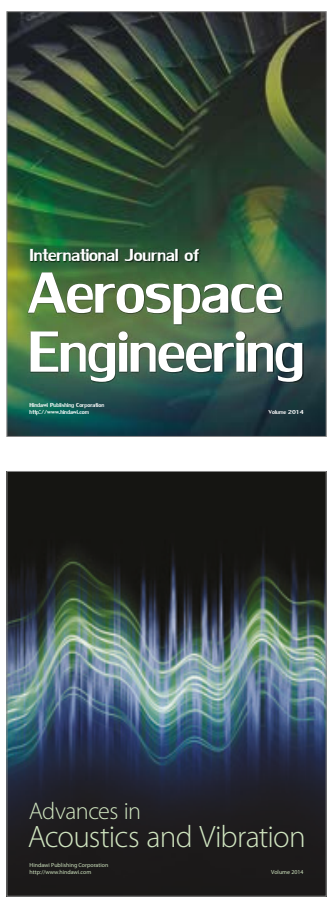

Sensor Networks 